\title{
Seminal vesicle interfraction displacement and margins in image guided radiotherapy for prostate cancer
}

Daisy Mak*, Suki Gill ${ }^{1}$, Roxby Paul ${ }^{2}$, Alison Stillie ${ }^{1}$ Annette Haworth², Tomas Kron², Jim Cramb², Kellie Knight Jessica Thomas', Gillian Duchesne ${ }^{1,4}$ and Farshad Foroudi ${ }^{1,4}$

\begin{abstract}
Background: To analyze interfraction motion of seminal vesicles (SV), and its motion relative to rectal and bladder filling.

Methods and Materials: SV and prostate were contoured on 771 daily computed tomography "on rails" scans from 24 prostate cancer patients undergoing radiotherapy. Random and systematic errors for SV centroid displacement were measured relative to the prostate centroid. Margins required for complete geometric coverage of SV were determined using isotropic expansion of reference contours. SV motion relative to rectum and bladder was determined.
\end{abstract}

Results: Systematic error for the SV was $1.9 \mathrm{~mm}$ left-right (LR), $2.9 \mathrm{~mm}$ anterior-posterior (AP) and $3.6 \mathrm{~mm}$ superior-inferior (SI). Random error was $1.4 \mathrm{~mm}(\mathrm{LR}), 2.7 \mathrm{~mm}(\mathrm{AP})$ and $2.1 \mathrm{~mm}(\mathrm{SI}) .10 \mathrm{~mm}$ margins covered the entire left SV and right SV on at least 90\% of fractions in 50\% and 33\% of patients and $15 \mathrm{~mm}$ margins covered $88 \%$ and $79 \%$ respectively. SV AP movement correlated with movement of the most posterior point of the bladder (mean $\mathrm{R}^{2}=0.46, \mathrm{SD}=0.24$ ) and rectal area (mean $\mathrm{R}^{2}=0.38, \mathrm{SD}=0.21$ ).

Conclusions: Considerable interfraction displacement of SV was observed in this cohort of patients. Bladder and rectal parameters correlated with SV movement.

Keywords: Seminal vesicle, Interfraction displacement, Margins, Prostate cancer, Radiotherapy

\section{Background}

In prostate cancer radiotherapy, proximal seminal vesicles (SV) are usually included in the clinical target volume (CTV) in intermediate to high risk prostate cancer. Bayman et al. conducted a review of prostatectomy series and revealed that the risk of SV invasion in intermediate risk patients is between 13 and $22 \%$ [1]. As a result, recommendations were made to encompass SV in patients with at least one risk factor of PSA $>10$, Gleason Score $\geq 7$, $\mathrm{T}$ stage $>2 \mathrm{~A}$, or percentage of positive biopsy $>50 \%$. Due to its proximity to rectum and bladder, SV inclusion may result in an increased rectal or bladder

\footnotetext{
*Correspondence: daisy.mak@petermac.org

'Radiation Oncology Division, Peter MacCallum Cancer Centre, Locked Bag 1, A'Beckett Street, East Melbourne, VIC 8006, Australia

Full list of author information is available at the end of the article
}

toxicity [2]. Methods which reduce SV CTV to planning target volume (PTV) margins may reduce side effects from radiotherapy.

Image guided radiotherapy (IGRT) is increasingly being used in the treatment of prostate cancer [3]. In IGRT, the prostate gland is localized before each fraction of treatment to allow for the correction of prostate displacement. This is usually performed without localization of the SV because SV are usually not visible on planar imaging and can be difficult to identify on cone beam computed tomography (CT).

Internal organ movement of the prostate is well documented in the literature [4]. SV motion has been relatively less well described, and is summarized in Table 1 . We aimed to use daily $\mathrm{CT}$ on rails images to i) quantify the inter-fraction SV displacement in relation to the centroid of prostate during a course of radiotherapy for

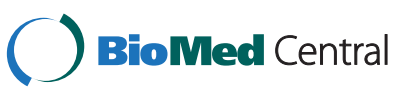


Table 1 Studies analysing seminal vesicle motion and margins

\begin{tabular}{|c|c|c|c|c|c|c|c|}
\hline Authors & $\begin{array}{l}\text { Movements } \\
\text { LR/AP/SI* }^{*}(\mathrm{~mm})\end{array}$ & Margins & Localisationt & Method for margins & Deformation & Patients & $\begin{array}{l}\text { Scans } \\
\text { per patient }\end{array}$ \\
\hline Current work & $\begin{array}{l}\text { Centre of volume: } \\
\text { Systematic 1.9/2.9/3.6. } \\
\text { Random 1.4/2.7/2.1 }\end{array}$ & $\begin{array}{l}\text { Geometric method approx } 15 \mathrm{~mm} \\
\text { (whole SV and inf } 2.5 \mathrm{~cm}) . \\
\text { Van Herk Formula approx } 10 \mathrm{~mm} .\end{array}$ & Prostate centroid & $\begin{array}{l}\text { Geometrical expansion of } \\
\text { reference SV contours, and } \\
\text { Van Herk Formula }\end{array}$ & Yes & 24 & 32 \\
\hline Frank et al. [7] & $\begin{array}{l}\text { Centre of volume: } \\
\text { Systematic 1.9/7.3/4.5. } \\
\text { Random 0.4/1.2/0.6 }\end{array}$ & $\begin{array}{l}\geq 10 \mathrm{~mm} 10 \mathrm{~mm} \text { covers } \mathrm{SV} \\
\text { AP variation in } 86 \% \text { of treatments }\end{array}$ & Pubic symphysis & Geometrical & No & 15 & 24 \\
\hline AHerne et al. [8] & N/A & $\begin{array}{l}5 \mathrm{~mm} \text { cover both SVs in } 56.2 \% \text { of } \\
\text { fractions, } 10 \mathrm{~mm} \text { cover } 95.5 \% \text {, } \\
15 \mathrm{~mm} \text { cover all }\end{array}$ & Prostate fiiducial markers & $\begin{array}{l}\text { Geometrical - margin to } \\
\text { cover fiducial marker in SV }\end{array}$ & No & 9 & $8-11$ \\
\hline $\begin{array}{l}\text { van der Wielen } \\
\text { et al. [14] }\end{array}$ & $\begin{array}{l}\text { Deformation + movement } \\
\text { approx } 3.0 \text { (1.7 in LR) }\end{array}$ & Approx 9-10 mm (illustrative). & Prostate fiducial markers & Van Herk Formula (illustrative) & Yes & 21 & 4 \\
\hline Mutanga et al. [15] & Used data above & $8 \mathrm{~mm}$ margin insufficient (IMRT) & Prostate fiducial markers & $\begin{array}{l}\text { Dose (simulation including } \\
\text { deformation with deformable } \\
\text { registration) }\end{array}$ & Yes & 21 & 4 \\
\hline Liang et al. [16] & $\begin{array}{l}\text { Maximize overlap of SV volume. } \\
\text { Systematic } 1.1 / 2.9 / 2.2 \text {. } \\
\text { Random 1.2/2.4/1.9 }\end{array}$ & Minimum margins $4.5 \mathrm{~mm}$ (IMRT) & $\begin{array}{l}\text { Prostate (maximize overlap of } \\
\text { 3D volume) }\end{array}$ & Dose (deformable registration) & Yes & 24 & 16 \\
\hline O'Daniel et al.[17] & N/A & $\begin{array}{l}\text { Study compared alignment technique } \\
\text { and found } 5 \mathrm{~mm} \text { margins give a } \\
\text { minimum of } 92 \% \text { of dose to } \\
\text { SV using IMRT }\end{array}$ & Prostate centroid & Minimum dose in any fraction & Yes & 10 & 24 \\
\hline Meijer et al. [18] & N/A & $8 \mathrm{~mm}$ (inferior $2 \mathrm{~cm}$ of SV) (IMRT) & Prostate fiducial markers & Dose (deformable registration) & Yes & 30 & 8 \\
\hline $\begin{array}{l}\text { Smitsmans } \\
\text { et al. [19] }\end{array}$ & $\begin{array}{l}\text { Image based registration of } \\
\text { central (sup/inf) part of SV } \\
\text { Systematic 1.6/2.8/- } \\
\text { Random 2.0/3.1/- }\end{array}$ & $4.6 \mathrm{~mm}$ LR $7.6 \mathrm{~mm}$ AP & Prostate fiducial markers & Van Herk Formula & No & 13 & 23 \\
\hline
\end{tabular}


prostate cancer, simulating IGRT targeting the prostate with translations (but not rotations), ii) assess geometrybased (rather than dose-based) margins required to completely cover the SV for any percentage of fractions, using isotropic expansion of reference contours to allow for both movement and deformation independent of treatment technique and iii) evaluate correlations between SV motion and changes in the rectum and bladder, two structures which may be easier to see than the SV themselves using soft tissue IGRT.

\section{Methods and materials}

\section{Patient demographics}

With human research ethical board approval, CT datasets of 24 consecutive patients treated radically for prostate cancer with daily pre-treatment $\mathrm{CT}$ on rails imaging were evaluated. Patient enrollment and treatment setup have been documented in our previous publication [5].

A total of 771 scans were obtained between the 24 patients (median 32 scans each, range 18 - 36). Median age was 72 years (range $55-78$ years). Eight of these patients were staged T1, 13 had T2 disease and 3 had T3 disease. Eleven patients had PSA $<10 \mathrm{ng} / \mathrm{ml}, 8$ had PSA $10-20 \mathrm{ng} / \mathrm{ml}$ and 5 had PSA $>20 \mathrm{ng} / \mathrm{ml}$. Gleason score was $\leq 6$ in 11 patients, 9 had Gleason score 7 and 4 had Gleason score $\geq 8$.

\section{Imaging and treatment}

Patients were treated to a total dose of 74 Gy in 37 fractions, 2 Gy per fraction, 5 days per week on a Siemens PRIMATOM (Siemens OCS, Concord, USA) linear accelerator. Patients were instructed to empty their bladder and rectum one hour before treatment and to drink $750 \mathrm{ml}$ of water. They were immobilized supine on a carbon fiber couch top with foot stocks and knee support. Initial setup was by alignment of three skin tattoos to lasers. Setup was verified by a pre-treatment CT scan prior to each fraction (from a Siemens SOMATOM diagnostic CT scanner, using the same couch top and mounted on rails). CT slices were reconstructed with $5 \mathrm{~mm}$ thickness and spacing. If the rectal diameter was over $4 \mathrm{~cm}$ on the pre-treatment $\mathrm{CT}$, the patient was taken off the bed and asked to empty their rectum before re-CT and treatment. The first pre-treatment CT for each patient was used as the reference image for movement analysis as this was closer in time to the rest of treatment than the planning scan.

\section{Volume delineation}

$\mathrm{CT}$ on rail images were imported into $\mathrm{XiO}^{\mathrm{TM}} \mathrm{CMS}$ (Elekta Ltd, Crawley, UK). Prostate, bladder and rectum were contoured by a single investigator (KK). Two investigators (DM, AS) contoured SV, with all the images in one patient study set contoured by the same investigator. At the start of the study both investigators contoured test cases and compared results to ensure their work was consistent.

\section{Displacement analysis}

The contours were exported as DICOM structure sets. Software was written in $\mathrm{C}++$ using the dicomlib toolkit (available at http://code.google.com/p/dicomlib/) to read the structure sets and calculate volumes and centroid positions using the original contours. Centres of volumes (centroids) were calculated for the entire SV, the inferior $2.5 \mathrm{~cm}$ and the tip (most superior slice) of the SV. The prostate centroid was used as the origin on each fraction, with the other centroid positions (i.e. SV movements) being reported relative to this point. Translational movement was measured, but not rotational displacement.

\section{Assessment of margins}

SV margins were assessed using two methods (i) the van Herk formula (margin $=2.5 \mathrm{x}$ systematic error $+0.7 \mathrm{x}$ random error) [6], and (ii) geometrically based on isotropic expansion of SV contours. For the second method, software was written to interpolate the reference SV contours onto a $1 \mathrm{~mm} \times 1 \mathrm{~mm} \times 1 \mathrm{~mm}$ grid. The left and right SV for each patient were considered separately. All voxels inside the contours were marked to form a volume. An isotropic 3D margin was applied to this reference SV volume (CTV) using convolution for each margin size. The margin size was increased in $1 \mathrm{~mm}$ increments. For each margin size, the appropriate (left or right) SV contours from each daily treatment scan were overlaid onto the voxel grid, after alignment of the prostate centroids, to check if the points forming the contours would fit inside the grown reference SV volume. If any part was outside by more than $1 \mathrm{~mm}$, coverage was considered as inadequate. This process was repeated with the inferior $2.5 \mathrm{~cm}$ of each SV considered.

\section{Correlation of SV movement with organ volume}

In order to obtain the average rectal area and volume, two separate methods were used in this study. All volumes were calculated by the software mentioned above.

\section{Method 1}

Method 1 was conducted to see if the volume of rectum adjacent to the SV correlated with day to day SV displacement since the rectum is more easily localized than SV on pretreatment imaging such as cone beam CT. Only the section of rectum adjacent to SV on the reference scan was used for analysis. To assess the rectal 
parameters during treatment, only the section of rectum in the same CT slice positions (relative to the prostate centroid) as on the reference scan was examined. Total rectal volume was measured, and area was calculated by dividing the volume by the slice width and the number of slices which contained rectum. If there was significant rectal movement during treatment, the number of $\mathrm{CT}$ slices containing rectum in the predefined CT slice positions could be smaller. In fact, there was significant rectal movement in two patients where there was no rectum seen in the correlating CT slices on treatment, and hence, method 2 was used to calculate rectal volume and area.

\section{Method 2}

Rectal volume and area were measured from the level of the prostate centroid to the recto-sigmoid junction. This method will be valid for all patients, however, correlations with SV movement was expected to be weaker as a longer length of rectum was considered, where a significant portion of rectum was not adjacent to SV.

\section{Statistical analysis}

Mean and standard deviation (SD) were used to describe the variation in volumes of relevant organs during the course of treatment. For the SV movement analysis, both systematic and random errors were calculated. Linear regression analyses were used to explore the correlation $\left(\mathrm{R}^{2}\right)$ of SV displacements in relation to contralateral SV displacement, bladder volume, motion of the most posterior point of the bladder, rectal area and rectal volume.

\section{Results}

Random and systematic error for SV displacements

Systematic and random displacement of SV centroids and margins from the van Herk formula are given in
Table 2. Differences between LSV and RSV were not statistically significant.

\section{Geometric margin based on isotropic SV expansion}

A margin of $15.6 \mathrm{~mm}$ was required to cover the whole left SV for $90 \%$ of fractions for $90 \%$ of the entire patient cohort. For the right SV, a margin of $16.5 \mathrm{~mm}$ was required. For the inferior $2.5 \mathrm{~cm}$ of left and right $\mathrm{SV}$, margins of $13.6 \mathrm{~mm}$ and $16.3 \mathrm{~mm}$ were required. (Figure 1, Figure 2). The mean margins required for each patient to cover $90 \%$ of the fractions were as follow: entire LSV $11.3 \mathrm{~mm}$ (SD $3.4 \mathrm{~mm}$ ), inferior $2.5 \mathrm{~cm}$ LSV $10.3 \mathrm{~mm}$ (SD $2.5 \mathrm{~mm}$ ), entire RSV $12.3 \mathrm{~mm}$ (SD $3.5 \mathrm{~mm}$ ), and inferior $2.5 \mathrm{~cm}$ RSV $11.2 \mathrm{~mm}$ (SD $3.3 \mathrm{~mm})$.

There were 13 patients with LSV and 15 patients with RSV which were longer than $2.5 \mathrm{~cm}$ on the reference scan. In this subgroup, the mean margins for each patient to cover $90 \%$ of their fractions were: entire LSV $12.1 \mathrm{~mm}$ (SD $3.6 \mathrm{~mm}$ ), inferior $2.5 \mathrm{~cm} \mathrm{LSV} 10.8 \mathrm{~mm}$ (SD $2.4 \mathrm{~mm}$ ), entire RSV $12.0 \mathrm{~mm}$ (SD $2.8 \mathrm{~mm}$ ), and inferior $2.5 \mathrm{~cm}$ RSV $11.0 \mathrm{~mm}$ (SD $2.9 \mathrm{~mm}$ ).

Figure 3 demonstrates the relationship between geometrical margins and systematic error (the amount by which the position of the SV centroid on the reference scan, relative to the prostate centroid, was not typical for the rest of the treatment, for example due to rectal gas in the reference scan.)

\section{Variation in volumes}

The mean superior-inferior (SI) length of SV on all CT images was $2.7 \mathrm{~cm}$ (range 1 to $4.5 \mathrm{~cm}$ with CT slice spacing of $0.5 \mathrm{~cm}$ ) for the left SV and $2.8 \mathrm{~cm}$ (range 1 to $5 \mathrm{~cm}$ ) for the right SV. In those patients (13 LSV, 15 RSV) where LSV or RSV was longer than $2.5 \mathrm{~cm}$ on the reference scan, the mean length on the reference scan

Table 2 Systematic and random errors for displacement of the three points of interest for the right seminal vesicle (RSV) and left seminal vesicle (LSV)

\begin{tabular}{|c|c|c|c|c|c|c|c|c|c|c|c|c|}
\hline & Direction & $\begin{array}{l}\text { Whole } \\
\text { LSV }\end{array}$ & $\begin{array}{l}\text { Whole } \\
\text { LSV* } \\
\text { (long) }\end{array}$ & $\begin{array}{l}\text { Inferior } \\
2.5 \mathrm{~cm} \\
\text { LSV }^{*}\end{array}$ & $\begin{array}{l}\text { LSV } \\
\text { tip }\end{array}$ & $\begin{array}{l}\text { Whole } \\
\text { RSV }\end{array}$ & $\begin{array}{l}\text { Whole } \\
\text { RSV* } \\
\text { (long) }\end{array}$ & $\begin{array}{l}\text { Inferior } \\
2.5 \mathrm{~cm} \\
\mathrm{RSV}^{*}\end{array}$ & $\begin{array}{l}\text { RSV } \\
\text { tip }\end{array}$ & $\begin{array}{l}\text { Whole } \\
\text { sV }+\end{array}$ & $\begin{array}{l}\text { Inferior } \\
2.5 \mathrm{~cm} \\
\mathrm{SV} \dagger\end{array}$ & $\begin{array}{l}\text { sV } \\
\text { tipt }\end{array}$ \\
\hline \multirow{3}{*}{$\begin{array}{l}\text { Systematic } \\
\text { error }(\mathrm{mm})\left(\sum\right)\end{array}$} & $L R$ & 1.5 & 1.3 & 1.3 & 3.3 & 2.1 & 1.6 & 1.7 & 4.4 & 1.9 & 1.9 & 4.2 \\
\hline & $\mathrm{AP}$ & 2.7 & 3.1 & 2.7 & 3.9 & 3.0 & 3.2 & 3.6 & 4.2 & 2.9 & 2.9 & 4.0 \\
\hline & $\mathrm{SI}$ & 3.1 & 3.4 & 3.5 & 4.0 & 4.1 & 3.3 & 3.1 & 5.8 & 3.6 & 3.5 & 5.0 \\
\hline \multirow{3}{*}{$\begin{array}{l}\text { Random } \\
\text { error (mm) ( })\end{array}$} & $L R$ & 1.3 & 1.3 & 1.3 & 3.3 & 1.5 & 1.6 & 1.5 & 3.9 & 1.4 & 1.4 & 3.6 \\
\hline & $\mathrm{AP}$ & 2.7 & 2.9 & 2.9 & 4.0 & 2.7 & 2.7 & 2.8 & 4.1 & 2.7 & 2.8 & 4.1 \\
\hline & $\mathrm{SI}$ & 2.1 & 2.1 & 2.1 & 3.5 & 2.1 & 2.3 & 2.2 & 3.5 & 2.1 & 2.1 & 3.5 \\
\hline \multirow{3}{*}{$\begin{array}{l}\text { van Herk } \\
\text { Margin (mm) }\end{array}$} & $L R$ & 4.7 & 4.2 & 4.2 & & 6.3 & 5.1 & 5.3 & & 5.7 & 5.7 & \\
\hline & $A P$ & 8.6 & 9.8 & 8.8 & & 9.4 & 9.9 & 11.0 & & 9.1 & 9.2 & \\
\hline & $\mathrm{SI}$ & 9.2 & 10.0 & 10.2 & & 11.7 & 9.9 & 9.3 & & 10.5 & 10.2 & \\
\hline
\end{tabular}

*Data from 13 LSV or 15 RSV, as the remaining SVs were shorter than $2.5 \mathrm{~cm}$ on the reference scan. 

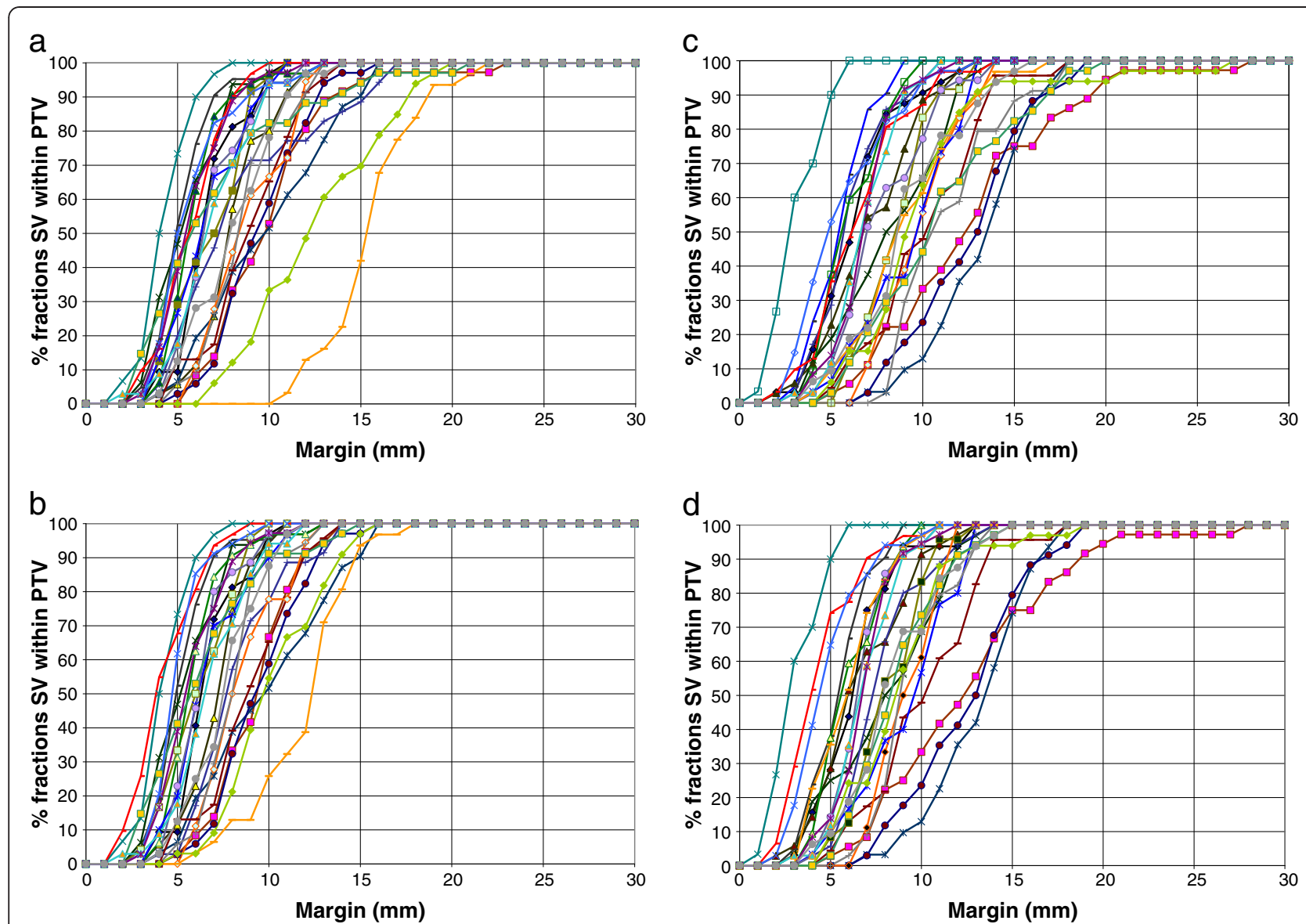

Figure 1 a) Margins required to cover the entire left seminal vesicle. Results for all 24 patients were plotted individually. b) Margins required to cover the inferior $2.5 \mathrm{~cm}$ portion of left seminal vesicle, c) entire right seminal vesicle and d) inferior $2.5 \mathrm{~cm}$ portion of right seminal vesicle. Same line colour has been used for each individual patients in Figure 1a - d.

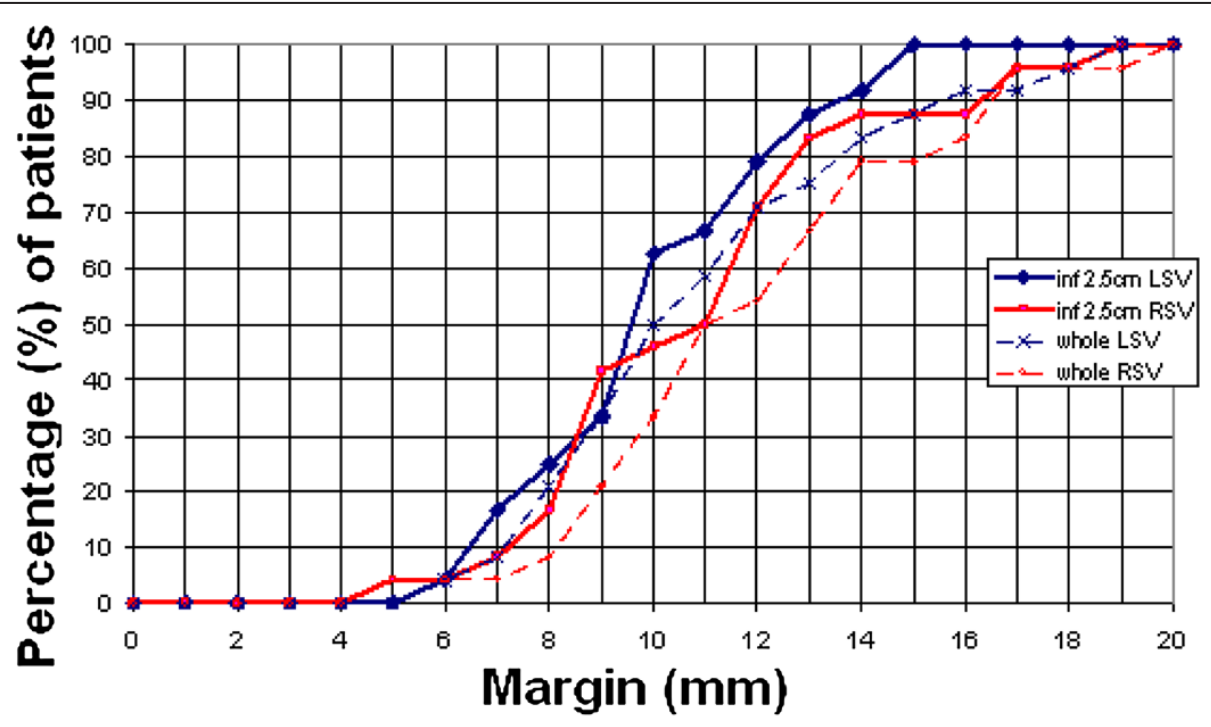

Figure 2 Percentage of patients where the entire or the inferior $2.5 \mathrm{~cm}$ of SV is within the PTV on at least $90 \%$ of the fractions. Data from all patients including those with $\mathrm{SVs} \leq 2.5 \mathrm{~cm}$ in length. 


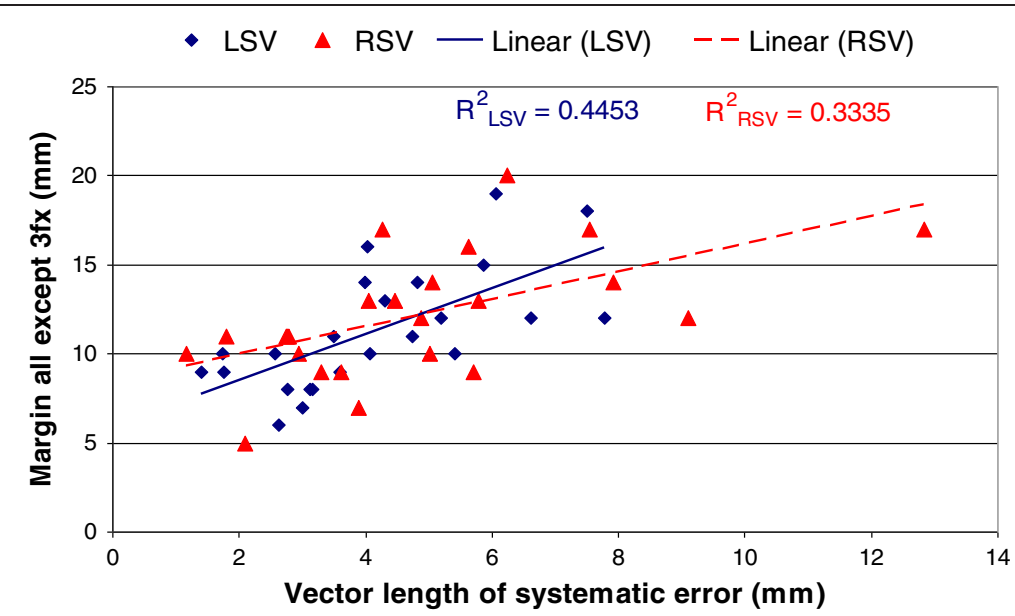

Figure 3 Relationship between the geometrical margin to cover SV and systematic error (average movement of the seminal vesicle centroid from its position in the reference scan, expressed as the length of the 3D vector). Three fractions were excluded as outliers which give margins that fit approximately $90 \%$ of all fractions.

was $3.3 \mathrm{~cm}$ for both LSV and RSV. Mean left SV, right SV and prostate volumes on the reference scan were $8.3 \mathrm{~cm}^{3}, 8.8 \mathrm{~cm}^{3}$ and $32 \mathrm{~cm}^{3}$ respectively. The SD of volume variations during treatment for LSV was $1.28 \mathrm{~cm}^{3}$, RSV $1.22 \mathrm{~cm}^{3}$, and prostate $4.58 \mathrm{~cm}^{3}$.

The mean bladder volume of all reference scans was $258 \mathrm{~cm}^{3}$. After some smoothing of day to day volume variation (median SD $62 \mathrm{~cm}^{3}$ ), three patients had a significant trend of bladder volume as treatment progressed $\left(R^{2}>0.2\right)$. For these three patients, bladder volume was reduced by $1.2 \%, 1.4 \%$ and $0.9 \%$ per fraction on average.

The mean rectal area (method 1) of all reference scans was $14.1 \mathrm{~cm}^{2}$ with a median day to day variation (SD) of $3.7 \mathrm{~cm}^{2}$. After smoothing, four patients had a significant trend as treatment progressed (defined as $R^{2}>0.2$ and change per day greater than $0.15 \mathrm{~cm}^{2}$ ). The rectal area for these four patients was reduced by $1.0 \%, 1.9 \%, 1.7 \%$ and $2.0 \%$ per fraction on average respectively.
SV displacement in relation to bladder, rectum and contralateral SV

Correlation of contralateral SV movements was seen in the SI $\left(R^{2}=0.72\right)$ and anterior-posterior $(\mathrm{AP})\left(\mathrm{R}^{2}=0.44\right)$ directions, but not in the left-right (LR) direction.

There was a weak association between AP SV motion and bladder volume. Out of twenty four, six left SV and seven right $\mathrm{SV}$ had a correlation $\left(\mathrm{R}^{2}\right) \geq 0.2$. However, a strong correlation was seen between AP movement of $\mathrm{SV}$ and the movement of the most posterior point of the bladder as shown in Figure 4. On a per patient basis the mean correlation $\left(\mathrm{R}^{2}\right)$ for the left $\mathrm{SV}$ was 0.46 with a SD of 0.23 . For the right $S V$, the mean correlation $\left(R^{2}\right)$ was 0.46 with a SD of 0.24 .

Correlation between SV movement and rectal area and volume is shown in Figure 5 and Table 3. Weak correlations (mean $R^{2} \sim 0.2$ ) were observed in the SI and $L R$ directions. Stronger correlations (mean $R^{2}$ up to 0.4 ) were observed in the AP direction with method 1 showing

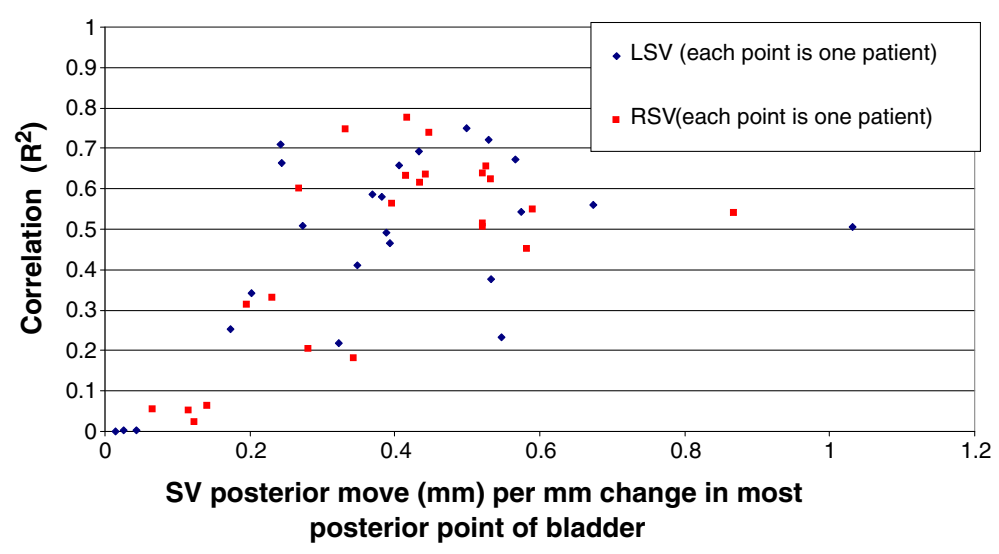

Figure 4 Correlation of SV AP movement with movement of the most posterior point of the bladder. 


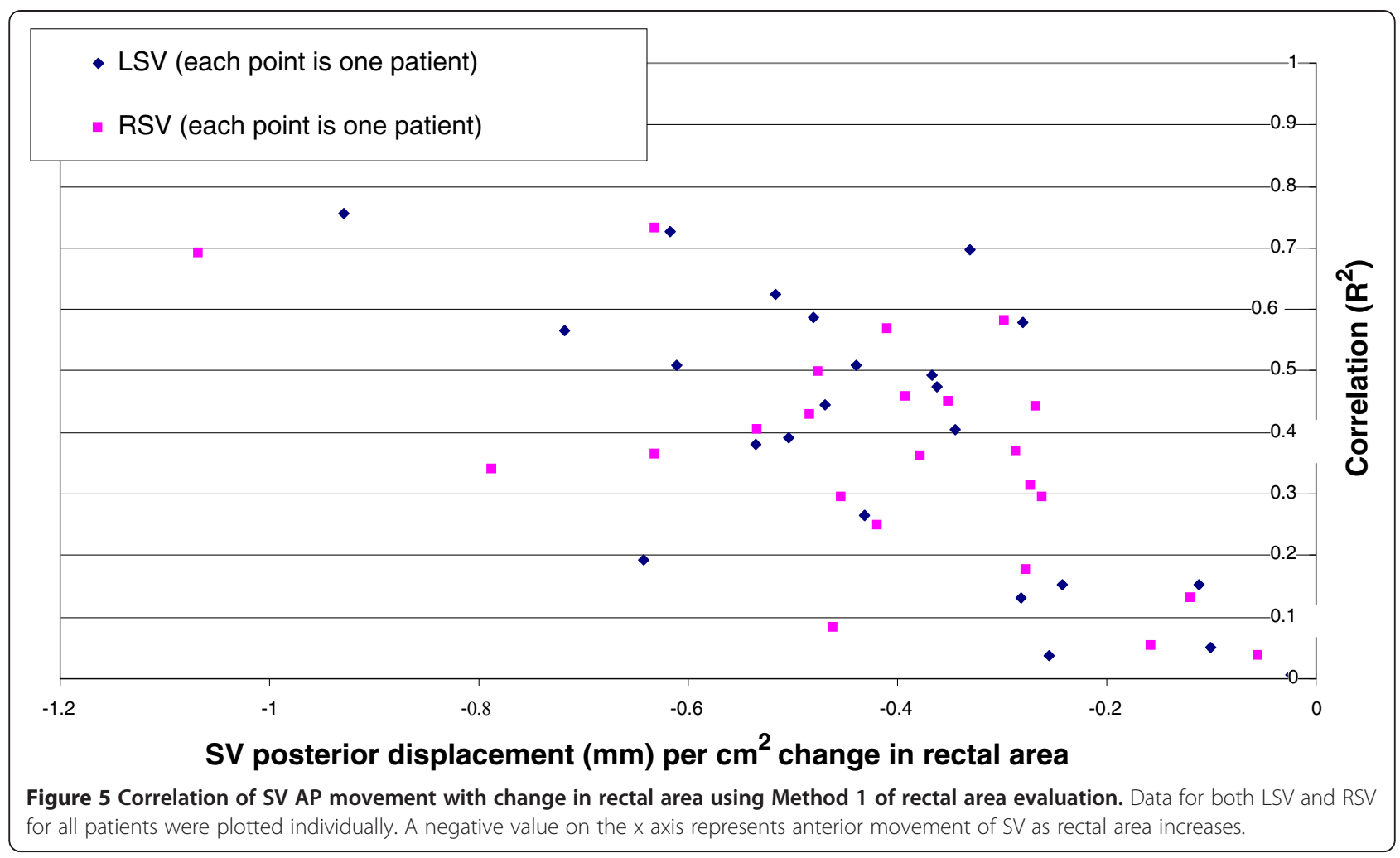

slightly stronger correlations than method 2 . Rectal area showed a slightly greater correlation than rectal volume with AP SV movement. Method 1 could not be used for $28 / 31$ fractions of one patient, and 2/34 fractions of a second patient, due to the recto-sigmoid junction moving to a position inferior to $\mathrm{SV}$ on the reference scan.

\section{Discussion}

This study assessed a large number of scans (median 32 per patient) for a considerable number of patients (24) and found considerable SV motion relative to the prostate. We looked at a sufficient number of patients to see some with large systematic errors requiring larger margins. Assessing a large number of pre-treatment CTs enabled us to use actual SV contours for the movement at each fraction, rather than assuming a normal distribution.

Table 1 gives an overview of the studies looking at SV movements and margins required for SV in radiotherapy. The papers using a dose-based analysis generally find considerably smaller margins, as do those when the prostate and SV were assessed in combination. Studies using prostate fiducial markers or the prostate centroid for localization report reasonably similar movements.

We estimated margins in two ways, using the van Herk formula, and by considering geometric coverage

Table 3 Rectal area and volume correlations with SV movements

\begin{tabular}{|c|c|c|c|c|c|c|c|c|c|}
\hline & & \multicolumn{4}{|c|}{ Rectal contour using Method ${ }^{*}$} & \multicolumn{4}{|c|}{ Rectal contour using Method $2^{*}$} \\
\hline & & \multicolumn{2}{|c|}{ Rectal area } & \multicolumn{2}{|c|}{ Rectal volume } & \multicolumn{2}{|c|}{ Rectal area } & \multicolumn{2}{|c|}{ Rectal volume } \\
\hline & & $\begin{array}{c}\text { Average } \\
\text { correlations }\left(\mathrm{R}^{2}\right)\end{array}$ & $\overline{S D}$ & $\begin{array}{c}\text { Average } \\
\text { correlations }\left(\mathrm{R}^{2}\right)\end{array}$ & $\overline{S D}$ & $\begin{array}{c}\text { Average } \\
\text { correlations }\left(\mathrm{R}^{2}\right)\end{array}$ & $\overline{S D}$ & $\begin{array}{c}\text { Average } \\
\text { correlations }\left(\mathrm{R}^{2}\right)\end{array}$ & SD \\
\hline \multirow[t]{2}{*}{ Ant/Post } & LSV & 0.40 & 0.23 & 0.37 & 0.22 & 0.38 & 0.24 & 0.35 & 0.21 \\
\hline & RSV & 0.36 & 0.19 & 0.35 & 0.16 & 0.35 & 0.21 & 0.33 & 0.17 \\
\hline \multirow[t]{2}{*}{ Sup/lnf } & LSV & 0.20 & 0.17 & 0.22 & 0.19 & 0.21 & 0.18 & 0.23 & 0.19 \\
\hline & RSV & 0.22 & 0.17 & 0.23 & 0.19 & 0.20 & 0.16 & 0.24 & 0.20 \\
\hline \multirow[t]{2}{*}{ Left/Right } & LSV & 0.19 & 0.19 & 0.19 & 0.19 & 0.21 & 0.20 & 0.17 & 0.18 \\
\hline & RSV & 0.18 & 0.18 & 0.15 & 0.18 & 0.20 & 0.18 & 0.15 & 0.17 \\
\hline
\end{tabular}

* Rectal contouring methods have been described in the Methods and Materials section. 
using an isotropic expansion from the reference CT. The van Herk formula estimates the probability of distribution of the cumulative dose over a population of patients, but excludes rotational errors and shape deviations. Our geometric analysis allows for rotation and deformation but ignores dose outside of the PTV. Both methods reported large margins, with the van Herk formula estimates closely approximating findings from other studies [7,8]. Larger margins of $15.6 \mathrm{~mm}$ and $16.5 \mathrm{~mm}$ were required to cover the whole left and right SV for $90 \%$ of fractions for $90 \%$ of the entire patient cohort in this study using the geometrical analysis. These resultant margins are not recommended for treatment purposes given the potential toxicities from dose to bladder and rectum. Moreover, small excursions of SV outside of the PTV have only a limited effect on the cumulative SV dose, particularly if different parts of SV are missed on different treatment fractions. Dose outside of the PTV is likely to be higher for the SV because dose "fall off" from the superior part of the prostate will contribute to dose to the SV. In addition, there are some limitations of our study. Although mitigated by the use of interpolation, our geometric method is limited by the $5 \mathrm{~mm}$ thick CT slice spacing, with the greatest limitation in the estimation of SI margin. As a result, reported movements of the SV tip will be less accurate than movements of the whole SV and inferior $2.5 \mathrm{~cm}$ portion. Uncertainty in manual contouring of SV on CT slices will have led to a slight increase in reported movement and margins. Combining these effects, margin for SV is likely to be much smaller than the geometrical margins reported here. Nevertheless, our data show that movement of SV relative to the prostate is substantial and should be considered when setting margins for conformal treatment techniques where daily setup is to the prostate, particularly as the dose outside the PTV is likely to be reduced as radiotherapy technology improves.

This study found that the margin required to cover the proximal $2.5 \mathrm{~cm}$ was only a little smaller than the margin required to cover the entire SV. Differences of up to $4 \mathrm{~mm}$ in the margin to treat $90 \%$ of fractions could be seen for a few patients but the average difference was $1.2 \mathrm{~mm}$. One might expect that displacement and hence margins were greater as distance increased from the prostate centroid. However, in those patients where the SV were longer than $2.5 \mathrm{~cm}$, it was frequently not very much larger (mean $3.3 \mathrm{~cm}$ for both LSV and RSV). This may explain why the difference in margin for the entire $\mathrm{SV}$ and proximal $2.5 \mathrm{~cm}$ were similar.

The extent of SV inclusion is a clinical judgment often individualized to the patient depending on the proximity of rectum and small bowel. Guidelines state however that either the proximal half [1], the proximal 1-2 cm [9] or at least the proximal $1 \mathrm{~cm}$ of SV should be included in the high risk CTV and treated to full dose [10]. A frequently quoted study from the William Beaumont Hospital looked at 81 positive SV from clinically staged $\leq \mathrm{T} 2 \mathrm{c}$ prostate cancer patients who subsequently underwent prostatectomy [11]. The pattern of SV invasion was contiguous in $86 \%$. Of those SV that were positive, $47 \%$ had SV involvement beyond the proximal 25\% of the SV, $14 \%$ had SV involvement beyond the proximal $50 \%$, and $2 \%$ were involved beyond the proximal $60 \%$. However, the question of length of SV requiring inclusion in the radiotherapy CTV is still incompletely answered. In addition, dose required to treat microscopic disease may be reduced. Further research is required.

Even with a standardized departmental setup protocol, we have noted that there can be significant changes in bladder volume and rectal filling during the course of radiotherapy for some patients. Bladder volumes in our study did not have a good correlation with SV displacement, but a strong correlation of SV AP movement with the position of the most posterior point of the bladder was observed. Correlations with rectal filling were also observed in our study, as by Frank et al. [7]. Therefore, patient education and monitoring of bladder and rectal parameters are encouraged to detect both random and particularly systematic movements. Systematic and random errors might also be reduced by the use of an endorectal balloon prior to each treatment to provide constant rectal volume [12].

In a study from the William Beaumont hospital, adaptive margins for prostate and SV were created using a bounding volume of daily pre-treatment imaging in the first week, or two weeks, of treatment which improved efficacy [13]. Supporting this, our data (Figure 1, Figure 3) show that for many patients margin size is reasonably consistent between fractions and has a component related to systematic error. Given the non-uniform SV movement as noted in this study, asymmetric margins could be explored in future studies with a smaller margin in the left-right direction.

\section{Conclusion}

Considerable interfraction SV displacement was observed in this cohort of patients with simulated IGRT targeting the prostate. Future radiotherapy technique design should not neglect SV motion. Correlation of SV motion with bladder and rectal parameters is observed.

Competing interests

The authors declare that they have no competing interest.

Authors' contribution

All authors read and approved the final manuscript. 


\section{Author details}

'Radiation Oncology Division, Peter MacCallum Cancer Centre, Locked Bag 1, A'Beckett Street, East Melbourne, VIC 8006, Australia. ²Physical Sciences Department, Peter MacCallum Cancer Centre, East Melbourne, VIC, Australia. ${ }^{3}$ Radiation Therapy Services, Peter MacCallum Cancer Centre, East Melbourne, VIC, Australia. ${ }^{4}$ Department of Pathology, The University of Melbourne, East Melbourne, VIC, Australia

Received: 6 March 2012 Accepted: 4 August 2012

Published: 13 August 2012

\section{References}

1. Bayman NA, Wylie JP: When should the seminal vesicles be included in the target volume in prostate radiotherapy? Clin Oncol (R Coll Radiol) 2007, 19:302-307.

2. Gluck I, Vineberg KA, Ten Haken RK, Sandler HM: Evaluating the relationships between rectal normal tissue complication probability and the portion of seminal vesicles included in the clinical target volume in intensity-modulated radiotherapy for prostate cancer. Int J Radiat Oncol Biol Phys 2009, 73:334-340.

3. Kupelian PA, Langen KM, Willoughby TR, Zeidan OA, Meeks SL: Imageguided radiotherapy for localized prostate cancer: treating a moving target. Semin Radiat Oncol 2008, 18:58-66.

4. Beard CJ, Kijewski P, Bussiere M, Gelman R, Gladstone D, Shaffer K, Plunkett M, Castello P, Coleman CN: Analysis of prostate and seminal vesicle motion: implications for treatment planning. Int J Radiat Oncol Biol Phys 1996, 34:451-458.

5. Knight K, Touma N, Zhu L, Duchesne GM, Cox J: Implementation of daily image-guided radiation therapy using an in-room CT scanner for prostate cancer isocentre localization. J Med Imaging Radiat Oncol 2009, 53:132-138.

6. van Herk M, Remeijer P, Rasch C, Lebesque JV: The probability of correct target dosage: dose-population histograms for deriving treatment margins in radiotherapy. Int J Radiat Oncol Biol Phys 2000, 47:1121-1135.

7. Frank SJ, Dong L, Kudchadker RJ, De Crevoisier R, Lee AK, Cheung R, Choi S, O'Daniel J, Tucker SL, Wang H, Kuban DA: Quantification of prostate and seminal vesicle interfraction variation during IMRT. Int I Radiat Oncol Biol Phys 2008, 71:813-820.

8. Aherne N, Herden J, Wood M, Schaeffer A, Hill J, Last A, Fuller C, Welshman R, Shakespeare T: Daily Fiducial Based Tracking of Seminal Vesicle Motion in Image Guided Dose Escalated IMRT: Are We Kidding Ourselves Regarding Seminal Vesicle Coverage? International Journal of Radiation Oncology* Biology* Physics 2009, 75:S297.

9. Boehmer D, Maingon P, Poortmans P, Baron MH, Miralbell R, Remouchamps V, Scrase C, Bossi A, Bolla M: Guidelines for primary radiotherapy of patients with prostate cancer. Radiother Oncol 2006, 79:259-269.

10. Hayden AJ, Martin JM, Kneebone AB, Lehman M, Wiltshire KL, Skala M, Christie D, Vial P, McDowall R, Tai KH: Australian \& New Zealand Faculty of Radiation Oncology Genito-Urinary Group: 2010 consensus guidelines for definitive external beam radiotherapy for prostate carcinoma. J Med Imaging Radiat Oncol 2010, 54:513-525.

11. Kestin L, Goldstein N, Vicini F, Yan D, Korman H, Martinez A: Treatment of prostate cancer with radiotherapy: should the entire seminal vesicles be included in the clinical target volume? Int J Radiat Oncol Biol Phys 2002, 54:686-697.

12. Miralbell R, Molla M, Arnalte R, Canales S, Vargas E, Linero D, Waters S, Nouet P, Rouzaud M, Escude L: Target repositioning optimization in prostate cancer: is intensity-modulated radiotherapy under stereotactic conditions feasible? Int J Radiat Oncol Biol Phys 2004, 59:366-371.

13. Yan D, Lockman D, Brabbins D, Tyburski L, Martinez A: An off-line strategy for constructing a patient-specific planning target volume in adaptive treatment process for prostate cancer. Int I Radiat Oncol Biol Phys 2000, 48:289-302.

14. van der Wielen GJ, Mutanga TF, Incrocci L, Kirkels WJ, Vasquez Osorio EM, Hoogeman MS, Heijmen BJ, de Boer HC: Deformation of prostate and seminal vesicles relative to intraprostatic fiducial markers. Int I Radiat Oncol Biol Phys 2008, 72:1604-1611. e1603.

15. Mutanga TF, de Boer HC, van der Wielen GJ, Hoogeman MS, Incrocci L, Heijmen BJ: Margin evaluation in the presence of deformation, rotation, and translation in prostate and entire seminal vesicle irradiation with daily marker-based setup corrections. Int J Radiat Oncol Biol Phys 2011, 81:1160-1167.

16. Liang J, Wu Q, Yan D: The role of seminal vesicle motion in target margin assessment for online image-guided radiotherapy for prostate cancer. Int I Radiat Oncol Biol Phys 2009, 73:935-943.

17. O'Daniel JC, Dong L, Zhang L, de Crevoisier R, Wang H, Lee AK, Cheung $R$, Tucker SL, Kudchadker RJ, Bonnen MD, et al: Dosimetric comparison of four target alignment methods for prostate cancer radiotherapy. Int $\mathrm{J}$ Radiat Oncol Biol Phys 2006, 66:883-891.

18. Meijer GJ, de Klerk J, Bzdusek K, van den Berg HA, Janssen R, Kaus MR, Rodrigus P, van der Toorn PP: What CTV-to-PTV margins should be applied for prostate irradiation? Four-dimensional quantitative assessment using model-based deformable image registration techniques. Int J Radiat Oncol Biol Phys 2008, 72:1416-1425.

19. Smitsmans MH, de Bois J, Sonke JJ, Catton CN, Jaffray DA, Lebesque JV, van Herk M: Residual seminal vesicle displacement in marker-based imageguided radiotherapy for prostate cancer and the impact on margin design. Int J Radiat Oncol Biol Phys 2011, 80:590-596.

doi:10.1186/1748-717X-7-139

Cite this article as: Mak et al: Seminal vesicle interfraction displacement and margins in image guided radiotherapy for prostate cancer. Radiation Oncology 2012 7:139.

\section{Submit your next manuscript to BioMed Central and take full advantage of:}

- Convenient online submission

- Thorough peer review

- No space constraints or color figure charges

- Immediate publication on acceptance

- Inclusion in PubMed, CAS, Scopus and Google Scholar

- Research which is freely available for redistribution

Submit your manuscript at www.biomedcentral.com/submit
C Biomed Central 